\title{
Real-time quantitative polymerase chain reaction (QPCR) to identify Myxobolus cerebralis in rainbow trout Oncorhynchus mykiss
}

\author{
Wade P. Cavender ${ }^{1}$, John S. Wood ${ }^{2}$, Madison S. Powell ${ }^{3}$, Kenneth Overturf ${ }^{3}$, \\ Kenneth D. Cain ${ }^{1, *}$ \\ ${ }^{1}$ Department of Fish and Wildlife Resources and the Aquaculture Research Institute, University of Idaho, 6th and Line Street, \\ Moscow, Idaho 83844-1136, USA \\ ${ }^{2}$ Pisces Molecular LCC, 2200 Central Avenue, Suite F, Boulder, Colorado 80301, USA \\ ${ }^{3}$ Hagerman Fish Culture Experiment Station, University of Idaho, 3059-F National Fish Hatchery Road, Hagerman, \\ Idaho 83616, USA
}

\begin{abstract}
This study describes the development of a TaqMan real-time quantitative polymerase chain reaction (QPCR) technique using the heat-shock protein 70 (Hsp 70) and 18S ribosomal DNA (18S rDNA) sequences to identify Myxobolus cerebralis and attempt to quantify infection severity within rainbow trout fry Oncorhynchus mykiss. Rainbow trout for this study were exposed to $M$. cerebralis under natural river conditions and examined for infection by histology, polymerase chain reaction (PCR) and QPCR analysis at 900 Celsius temperature units (CTUs) following exposure. Detection sensitivity by QPCR was shown to be equal to traditional PCR but greater than histopathology. Primer/probe combinations developed for this study were capable of specifically detecting $M$. cerebralis DNA in infected fish tissue and single triactinomyxon (TAM) spores with a sensitivity of 12.5 and $6.3 \mathrm{pg} \mathrm{pl}^{-1}$ of DNA for the Hsp 70 and $18 \mathrm{~S}$ rDNA sequences, respectively. A strong relationship between QPCR and infection severity was found for the Hsp 70 probe when parasite copy number and histology scores of $0-4$ were compared $\left(R^{2}=0.96, p=0.003\right)$. However, a reduction in copy number was observed at higher histology scores for the 18S probe (scores of 4 and 5) and the Hsp 70 probe (score of 5). The results of this study demonstrate that QPCR analysis is an effective tool for detecting $M$. cerebralis in fish tissue and may provide a relative indication of infection severity.
\end{abstract}

KEY WORDS: Myxobolus cerebralis - Quantitative polymerase chain reaction - Histopathology · Hsp $70 \cdot 18 \mathrm{~S}$ rDNA

Resale or republication not permitted without written consent of the publisher

\section{INTRODUCTION}

Widespread distribution (Hoffman 1990, Bartholomew \& Reno 2002) and reduced survival in wild rainbow trout Oncorhynchus mykiss associated with whirling disease (Walker \& Nehring 1995, Vincent 1996) have increased the need to rapidly diagnose infections by Myxobolus cerebralis. The principal methods used to identify the parasite include pepsintrypsin digest (PTD) (Markiw \& Wolf 1974), histopathology (Lorz \& Amandi 1994, Hedrick et al. 1999, Baldwin et al. 2000 as modified by Andree et al.
2002) and polymerase chain reaction (PCR) analysis (Andree et al. 1998, Schisler et al. 2001, Baldwin \& Myklebust 2002). Histopathology and PTD analysis can also be used to determine infection severity, but both techniques lack sensitivity for detecting low-level infections. Although myxospore enumeration, as determined from PTD analysis, represents a relative level of infection, spore proliferation and virulence of $M$. cerebralis infection can be influenced by environmental conditions and host life-stages; therefore this technique is typically not used as the primary measure of severity (Nehring \& Walker 1996). In addition, peri- 
ods of 3 to 11 mo may be required to allow spore development to occur and PTD analysis to be performed (Andree et al. 2002).

PCR analysis is currently the most sensitive method available for detecting Myxobolus cerebralis, but infection intensity cannot be estimated by PCR. Although effective for clinical diagnosis, the above procedures can be time-consuming, labor-intensive and subjective in their ability to distinguish $M$. cerebralis from other closely related myxozoan species. Based on this and a need to further develop rapid diagnostic capabilities, we initiated a study to determine if a real-time quantitative polymerase chain reaction (QPCR) assay would be an effective method for detecting $M$. cerebralis DNA within infected fishes and quantifying infection severity during early myxospore development.

QPCR assays have been established for a number of fish pathogens (Overturf et al. 2001, del Cerro et al. 2002, Bilodeau et al. 2003, Corbeil et al. 2003) and offer a number of potential advantages. This technique is similar to traditional PCR in that it requires a series of short oligonucleotide primers for amplification of target sequences. However, in addition to duel primer sets, QPCR utilizes a sequence-specific fluorescent probe. During polymerization, this probe is cleaved, resulting in a level of fluorescence that can be quantified as a relative measure of template material when compared to a known standard. Fluorescence can then be visualized and measured using computer-based programs, therefore eliminating the need for the post-gel visualization required for traditional PCR techniques.

Molecular markers selected for PCR-based assays generally target gene sequences that are highly conserved and species-specific. The current PCR-based assay for Myxobolus cerebralis targets a ribosomal sequence (Andree et al. 1998, Kelley et al. 2004), but a specific assay based on the heat-shock protein 70 (Hsp 70) gene of this parasite has recently been developed (Epp et al. 2002). Targeting ribosomal genes is common since they are found in all living systems and control the synthesis of protein from messenger RNA (mRNA) (Hillis \& Dixon 1991). The highly conserved nature of these genes is useful for species identification (Hillis \& Dixon 1991), and PCR will typically yield a high degree of sensitivity associated with the presence of several sequence copies/genome (Bialek et al. 2000). Another gene that is highly conserved and important in living organisms is the heat-shock protein gene. Heat-shock proteins function as molecular chaperons that bind to other proteins and assist with folding and native confirmation required for protein:protein interactions (Feder \& Hofmann 1999). These genes are often used as phylogenetic indicators to distinguish between large groups of organisms (Feder \& Hofmann
1999), and multiple copies per genome are generally present. Therefore, the Hsp 70 and $18 \mathrm{~S}$ ribosomal DNA (18S rDNA) genes are ideal candidates for development of a QPCR analysis for M. cerebralis.

As a fish becomes infected and the etiological agent begins to replicate within its host, a pathogen's genetic copy or DNA concentration should increase as infection progresses. By using gene-specific probes, QPCR analysis should be capable of detecting increasing pathogen loads or possible carrier states within the host. This has been suggested for a number of fish pathogens including infectious haematopoietic necrosis virus (IHNV), Flavobacterium psychrophilum and Edwardsiella ictaluri (Overturf et al. 2001, del Cerro et al. 2002, Bilodeau et al. 2003). Potential benefits from a QPCR assay for Myxobolus cerebralis include sensitivity associated with PCR methodology, reduced labor, and potentially cost. A combined analysis may be capable of determining the presence and severity of infection within a single analysis. Reduced labor and cost could also be associated with the potential to examine infected fish tissues prior to myxospore development, ultimately eliminating the need for extensive rearing periods following parasite exposure in laboratory-based studies. Therefore, the objectives of this study were to (1) design and test primer/probe combinations specific for $M$. cerebralis based on the Hsp 70 and 18S rDNA gene sequences, (2) determine specificity and sensitivity of the QPCR technique in relation to current diagnostic methods, and (3) identify potential relationships, during early stages of infection, between the parasite's genetic copy number and infection intensity within rainbow trout.

\section{MATERIALS AND METHODS}

QPCR primer/probe design and instrumentation. A partial 581 base-pair nucleotide sequence from the Hsp 70 gene (Accession No. AY553906) for Myxobolus cerebralis was isolated and characterized by Pisces Molecular LCC using PCR amplification with degenerate primers (Epp et al. 2002). Dr. J. Wood provided this Hsp 70 nucleotide sequence, and the 18S rDNA gene sequence was obtained from GenBank (Accession No. U96492). Primer/probe combinations from both sequences were designed using Primer Express Software version 1.5 (Applied Biosystems). A BLAST search (Altschul et al. 1997) to identify homology of primer/probe combinations with other genetic sequences within the GenBank database was performed to determine potential for non-specific amplification. Primers were synthesized by Integrated DNA Technologies and probes were constructed by Applied Biosystems. 
Hsp 70. Forward 414F, 5'-CGAAGAACTCAATGGCTGATCTT-3' and reverse 471R, 5'-TTGCTCAATTTTGCATCACGTAA-3' primers were designed to amplify an 80 base-pair region of the Hsp 70 sequence for Myxobolus cerebralis. The TaqMan probe 448P, 5'-TCTTGACCCCGTTGAGAA-3' was designed with the fluorescent reporter 6-carboxyfluorescein (FAM-6) linked to the $5^{\prime}$ end and a proprietary (Applied Biosystems) non-fluorescent quencher (NFQ) attached to a minor groove-binding molecule (MGB) which was linked to the 3 ' end.

Prior to analysis, all samples were standardized to $20 \mathrm{ng}^{-1} \mathrm{l}^{-1}$ total DNA using a Perkin Elmer MBA 2000 spectrophotometer. Reaction conditions for the Hsp 70 sequence were established to provide optimal amplification and were thereafter performed as follows: reaction volume was $20 \mu \mathrm{l}$ and contained $1 \times$ TaqMan universal master mix (Applied Biosystems), $0.6 \mu \mathrm{M}$ forward primer, $0.6 \mu \mathrm{M}$ reverse primer, $0.8 \mu \mathrm{M}$ fluorescent labeled probe, and $20 \mathrm{ng} \mathrm{\mu l}^{-1}$ DNA. The $20 \mu \mathrm{l}$ reaction was transferred to individual wells of a 96-well optical plate (Applied Biosystems), capped, and placed in a BioRad iCycler real-time PCR detection system (BioRad Laboratories). Duplicate wells of no template controls (NTC) were incorporated into each 96-well plate to test for cross contamination between samples. The amplification profile consisted of initial denaturing at $95^{\circ} \mathrm{C}$ for $10 \mathrm{~min}$, followed by 45 cycles of $15 \mathrm{~s}$ at $95^{\circ} \mathrm{C}$ and $1 \mathrm{~min}$ at $60^{\circ} \mathrm{C}$. All samples were analyzed in duplicate to demonstrate repeatability.

$18 \mathrm{~S}$ rDNA. Forward 811F, 5'-TGAATAAATCAGAGTGCTCAAAGC-3' and reverse 937R, 5' GCTGTATGCTGTAACTG-3' primers were designed to amplify a 140 base-pair region of the $18 \mathrm{~S}$ rDNA sequence for Myxobolus cerebralis. The TaqMan probe 888P, 5'-TGTGACAAATAGCG-3' was designed with the same fluorescent reporter and quencher system described above. Sequence position within the Hsp 70 and 18S rDNA genes are shown in Table 1.
Reactions for the 18S rDNA sequence were established to provide optimal conditions for amplification and were thereafter performed as follows: reaction volume was $20 \mu \mathrm{l}$ and contained 1× TaqMan universal master mix (Applied Biosystems), $0.15 \mu \mathrm{M}$ forward primer, $0.15 \mu \mathrm{M}$ reverse primer, $0.2 \mu \mathrm{M}$ fluorescent

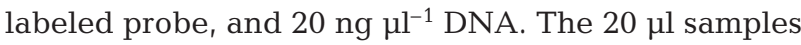
were prepared and inserted into the iCycler detection system as previously described. The amplification profile consisted of initial denaturing at $95^{\circ} \mathrm{C}$ for $10 \mathrm{~min}$, followed by 40 cycles of $15 \mathrm{~s}$ at $95^{\circ} \mathrm{C}$ and $1 \mathrm{~min}$ at $62^{\circ} \mathrm{C}$. All samples were again analyzed in duplicate to demonstrate repeatability.

PCR amplification with QPCR primer combinations. Primer combinations for the Hsp 70 and 18S rDNA sequences were first examined by conventional PCR analysis. Reaction volumes were $25 \mu \mathrm{l}$ and contained 1× Qiagen PCR buffer, $2.5 \mathrm{mM} \mathrm{MgCl}{ }_{2}, 0.6 \mu \mathrm{m}$ dNTPs, $2 \mathrm{U}$ Taq polymerase, and $0.6 \mu \mathrm{M}$ of each primer. Gradient conditions followed previously established protocols (Baldwin \& Myklebust 2002) and amplification was performed using a PTC-100 thermal cycler (MJ Research).

Standard design. The amplified region of the Hsp 70 gene was cloned into the pGEM $^{\circledR}$-T Easy Vector (Promega) and the amplified region of the 18S rDNA gene was cloned into the $\mathrm{pCR}^{\circledR} \mathrm{II}-\mathrm{TOPO}{ }^{\circledR}$ Vector using the Zero Blunt ${ }^{\oplus} \mathrm{TOPO}{ }^{\circledR} \mathrm{PCR}$ Cloning Kit (Invitrogen) following the manufacturers' protocols. Inserts were sequenced at Washington State University's DNA sequencing laboratory (Pullman) using an Applied Biosystems 3100 genetic analyzer to the confirm presence of appropriate inserts. The nucleotide length of each plasmid was counted and concentration was determined by $\mathrm{OD}_{260}$ using a Perkin Elmer MBA 2000 spectrophotometer. The values obtained were used to determine the relationship between the concentration of plasmid DNA and its copy number, according to the formula described by Yin et al. (2001). A set of 10-fold serial dilutions from 2 replicates was used to generate

Table 1. Primer and probe locations for detection of Myxobolus cerebralis. $T_{\mathrm{m}}$ : melting temperature; FAM: fluorescent reporter; NFG-MGB: non-fluorescent quencher attached to minor groove binding molecule

\begin{tabular}{|c|c|c|c|}
\hline Primers and probe & Sequence $\left(5^{\prime}-3^{\prime}\right)$ & Sequence position & $T_{\mathrm{m}}\left({ }^{\circ} \mathrm{C}\right)$ \\
\hline \multicolumn{4}{|l|}{ Hsp 70} \\
\hline Forward primer (414F) & CGAAGAACTCAATGGCTGATCTT & $414-436$ & 58.2 \\
\hline Reverse primer (471R) & TTGCTCAATTTTGCATCACGTAA & $471-493$ & 59.3 \\
\hline Probe $(448 \mathrm{P})$ & (FAM)-TCTTGACCCCGTTGAGAA-(NFG-MGB) & $448-466$ & 68.5 \\
\hline \multicolumn{4}{|l|}{ 18S rDNA } \\
\hline Forward primer $(811 \mathrm{~F})$ & TGAATAAATCAGAGTGCTCAAAGC & $811-833$ & 56.6 \\
\hline Reverse primer (937R) & TTGGTGCTGTATGCTGTAACTG & $937-958$ & 55.3 \\
\hline Probe $(888 \mathrm{P})$ & (FAM)-TGTGACAAATAGCG-(NFG-MGB) & $888-892$ & 64.2 \\
\hline
\end{tabular}


standard curves from the above plasmids for subsequent QPCR analysis. Linearity was determined through regression of the standard curve. Quantification of target DNA was determined by comparing critical threshold $(\mathrm{Ct})$ values, which represents that portion of the exponential level of fluorescence that can be detected in the QPCR reaction from unknown samples with that derived from a known standard. Ct values are inversely proportional to the starting quantity of template DNA and can therefore be used as a relative indicator of template material in the absence of a standard curve. Prior to analysis, infected fish samples and plasmid standards were run in unison to ensure that amplification profiles were similar and that samples would fall within the range of the standard curve (data not shown).

Assay specificity. To demonstrate assay specificity, controls consisted of DNA isolated from several closely related organisms including Myxobolus neurobious, M. insidiosus and M. squamalis. In addition, DNA preparations from Ceratomyxa shasta and Henneguya salmonicola, 2 parasites known to infect salmonids (Noga 1996, Hoffman 1999), were also used to test assay specificity. We obained 20 rainbow trout fry Oncorhynchus mykiss from a group of fish that had previously been determined negative for infection by nested PCR and histological analyses (Cavender et al. 2003), and used these to test for non-specific amplification of host tissue. These samples were randomly distributed throughout a 96-well optical plate and analyzed by PCR using both primer/probe sets.

Assay sensitivity. Triactinomyxon (TAM) spores obtained from C. Whipp at Oregon State University and E. MacConnell at Montana Fish, Wildlife and Parks, were enumerated using a glass microscope slide, $2 \mu \mathrm{l}$ pipette and a light microscope. Nucleic acid was extracted from 20 TAM spores using standard reagents, microfiltration tubes and standard protocols outlined in Qiagen's DNeasy tissue kit. The nucleic acid concentration of this extraction was determined using a spectrophotometer. To demonstrate assay sensitivity, detection limits were examined with 10and 2-fold serial dilutions from the above preparation using primer/probe combinations developed for both the Hsp 70 and 18S rDNA sequences. In addition, single TAM spores were placed in $5 \mu$ of $\mathrm{ddH}_{2} \mathrm{O}$ (double distilled water), denatured for $10 \mathrm{~min}$ at $100^{\circ} \mathrm{C}$, and examined by QPCR analysis.

Histopathology and PCR analysis. Samples for use in this study were obtained from 107 rainbow trout fry exposed to Myxobolus cerebralis under natural river conditions (Cavender et al. 2003). Following exposure, fish were maintained until 900 CTUs (Celcius temperature units) had accumulated to allow pathology and early spore development to occur. At
900 CTUs, fish were euthanized with $200 \mathrm{mg} \mathrm{l}^{-1}$ tricane methane sulfonate (MS-222; Argent Laboratories), decapitated, and their heads split sagitally. From each specimen, 1 half-head was processed for histological analysis at Washington's Animal Disease and Diagnostic Laboratory (WADDL) located at Washington State University (Pullman). Slides were stained with hematoxylin and eosin, examined under a light microscope, and graded for infection intensity according to the MacConnell/Baldwin (M/B) scale of infection for M. cerebralis (Baldwin et al. 2000, as modified by Andree et al. 2002). Infection severity, as determined by histopathology, ranged from $0-5$, with 0 indicating absence and 5 representing the most severe grade of infection.

The second half-head from each specimen was prepared for PCR analysis using a $6 \mathrm{~mm}$ biopsy punch (Miltex Instruments Company) to remove tissue containing cartilage and bone located at the base of the skull. Nucleic acid extractions and reaction conditions were performed as described by Cavender et al. (2003). All samples were analyzed with a single-round PCR analysis (Baldwin \& Myklebust 2002). When examining lightly infected fish, it has been demonstrated that single-round PCR is less sensitive than the nested PCR for Myxobolus cerebralis (Kelley et al. 2004). Therefore, those samples determined negative by single-round PCR were further examined by nested PCR following previously established protocols (Andree et al. 1998). Tissues from fish examined by histopathology and PCR were analyzed using QPCR to provide a relative comparison of specificity and sensitivity between diagnostic methods.

Statistical analysis. To ensure that replicates for both Hsp 70 and 18S rDNA could be combined for statistical analysis, differences in copy number between duplicate wells were analyzed using a paired $t$-test. As no difference between replicate wells for either Hsp 70 $(\mathrm{p}=0.94)$ or $18 \mathrm{~S}$ rDNA $(\mathrm{p}=0.82)$ was found, replicates were combined and mean values were used for further analysis. Copy numbers for both sequences did not meet normality assumptions and were subsequently $\log _{10}$-transformed prior to examination. Detection prevalence for Myxobolus cerebralis-infected fish was analyzed as a categorical variable across all diagnostic methods using a chi-square test for proportion differences. Linearity for both standards was evaluated using regression of the linear curve as calculated by the iCycler real-time PCR detection system. Association between histology scores and mean copy number from the Hsp 70 and 18S rDNA sequences was examined using general linear regression. Significance throughout this study was defined as $\mathrm{p}<0.01$ and statistical analysis was conducted using the SAS software program, Version 8.2. 


\section{RESULTS}

\section{PCR amplification and species-specificity}

Initial amplification of the appropriate nucleotide sequence for the Hsp 70 and 18S rDNA genes was done by PCR analysis using 150 and $20 \mathrm{ng} \mathrm{hl}^{-1}$ of Myxobolus cerebralis DNA, respectively. Amplification of the 80 base-pair region from the Hsp 70 sequence and the 140 base-pair region from the 18S rDNA sequence was verified by agarose gel $(2.0 \%)$ electrophoresis following PCR amplification (data not shown). Specificity of primer/probe combinations developed for both sequences was then optimized for QPCR analysis using DNA preparations from rainbow trout (host DNA only) and 5 fish parasites common to salmonids of the Pacific NW and capable of coexisting with M. cerebralis (Hoffman 1999). Both sets were determined to be specific only for $M$. cerebralis and did not react with host DNA (data not shown).

\section{Assay sensitivity}

A set of 10-fold serial dilutions of DNA extracted from 20 TAM spores (concentrations ranging from 25 to $0.25 \mathrm{pg}^{-1} \mathrm{l}^{-1}$ ) was amplified using QPCR analysis. Positive amplification for both the Hsp 70 and $18 \mathrm{~S}$ rDNA sequences was equivalent to $12.5 \mathrm{pg} \mathrm{hl}^{-1}$ (Table 2). A set of 2-fold serial dilutions of DNA extracted from TAM spores (concentrations ranging

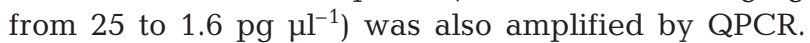
The lowest detectable DNA concentrations for the Hsp 70 and $18 \mathrm{~S}$ rDNA sequences were equivalent to 12.5 and $6.3 \mathrm{pg} \mathrm{pl}^{-1}$, respectively. Primer/probe combinations for both genes were capable of detecting single TAM spores following a short denaturing protocol. However, the copy number for single TAM spores ranged from 1-7.

Table 2. Results summarizing sensitivity of Hsp 70 and 18S rDNA QPCR analysis. Amplification above no template control (copy number $=0$ ) was considered positive

\begin{tabular}{|lcccc|}
\hline $\begin{array}{l}\text { Triactinomyxon } \\
\text { spores }\end{array}$ & $\begin{array}{c}\text { Dilution } \\
\text { series }\end{array}$ & $\begin{array}{c}\text { DNA conc. } \\
\left({\left.\mathrm{pg} \mu \mathrm{l}^{-1}\right)}\right.\end{array}$ & Hsp 70 & 18S rDNA \\
\hline 20 & 1 & 25000 & + & + \\
2 & $1 / 10$ & 2500 & + & + \\
0.2 & $1 / 10$ & 250 & + & + \\
0.02 & $1 / 10$ & 25 & + & + \\
0.01 & $1 / 1$ & 12.5 & + & + \\
0.005 & $1 / 1$ & 6.3 & - & + \\
0.0025 & $1 / 1$ & 3.2 & - & - \\
0.0013 & $1 / 1$ & 1.6 & - & - \\
\hline
\end{tabular}

Standard design and linearity

Nucleotide length and plasmid concentration was used to calculate copy number for each standard. Thus, $1 \mathrm{\mu g}$ of DNA was calculated to be equivalent to $2.9 \times$ $10^{9}$ and $2.27 \times 10^{9}$ copies for the Hsp 70 and $18 \mathrm{~S}$ rDNA sequences, respectively. We analyzed 10 -fold serial dilutions of each standard by QPCR, and their Ct values were plotted against starting quantity for each plasmid. Regression of the slope for the Hsp 70 standard was -3.435 and the equation of the line was $y=$ $-3.435 x+38.195$. Regression of the slope for the $18 \mathrm{~S}$ rDNA standard was -3.461 and the equation of the line was $y=-3.461 x+35.018$. Linearity was demonstrated for both the Hsp 70 and 18S rDNA standards, with correlation coefficients corresponding to 0.995 and 0.997, respectively (Fig. 1).

\section{Analysis of experimentally infected fish}

Sentinel rainbow trout previously exposed to Мухоbolus cerebralis under natural river conditions (Cavender et al. 2003) were examined for infection by histopathology, PCR, and QPCR analyses. Of the 107 fish examined, 32 were determined negative for infection by histology (Table 3). Fish analyzed by histology were also examined by single-round PCR, nested PCR, and QPCR using the primer/probe combinations developed for the Hsp 70 and 18S rDNA sequences. All fish that tested negative for infection by single-round PCR were also negative by nested PCR. Therefore, data from this analysis were combined and hereafter referred to as PCR analysis. Of 32 fish determined negative by histology, $9(28 \%)$ were positive for infection by PCR and QPCR using both primer/probe combinations. All fish determined positive for infection by histology were also positive by PCR and QPCR analyses. Detection by the PCR-based methodology was shown to be more sensitive, but when analyzed across all severity levels was not significantly greater than that observed for histology $(p=0.213)$. However, significantly greater detection of $M$. cerebralis-infected fish was shown to occur by PCR and QPCR among those fish determined negative by histology $(p=0.008)$.

\section{Infection severity and genetic copy number}

The copy number for the Hsp 70 gene increased with increasing histology scores of $0-4$, but decreased with a histology score of 5 (Fig. 2). The copy number for the $18 \mathrm{~S}$ 
Correlation coefficient: 0.997 Slope: -3.461 Intercept: $35.018 y=-3.461 x+35.018$

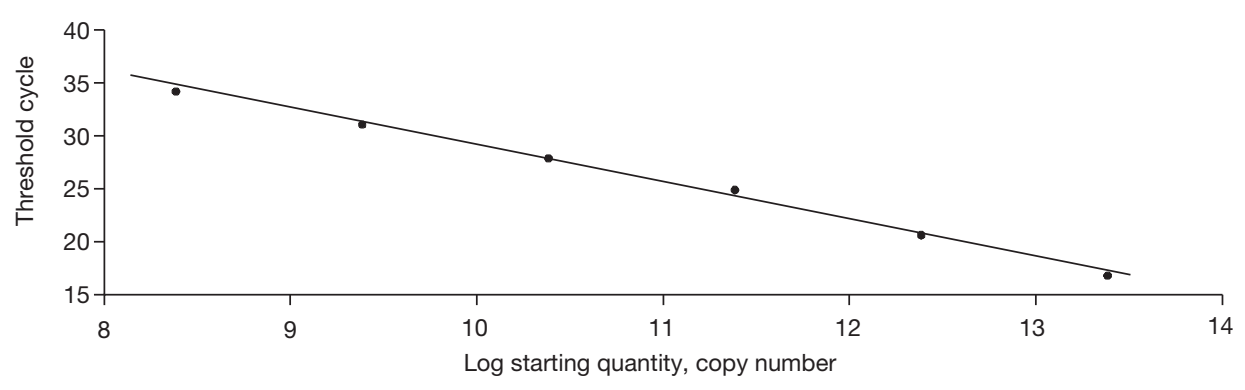

Correlation coefficient: 0.995 Slope: -3.435 Intercept: $38.195 y=-3.435 x+38.195$

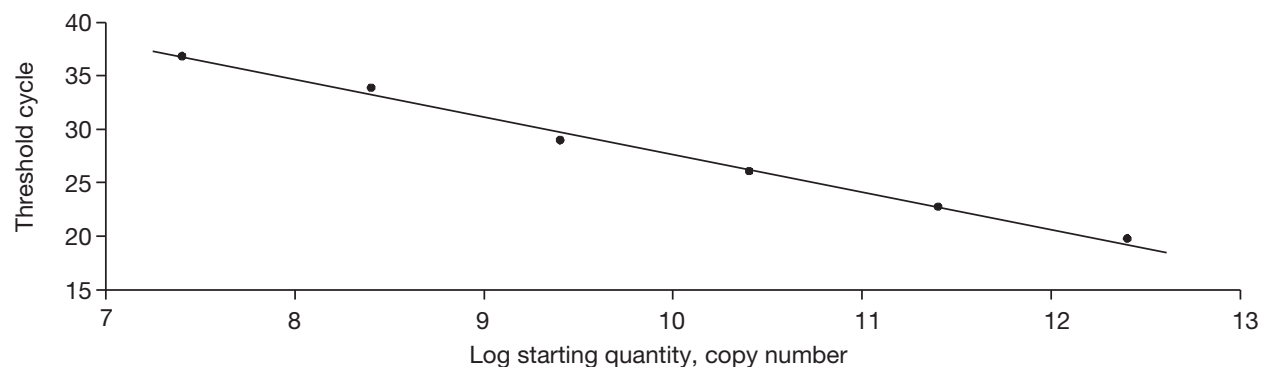

A

B Fig. 1. Standard curve derived from (A) Hsp 70 and (B) $18 \mathrm{~S}$ rDNA assays for quantification of Myxobolus cerebralis. $\mathrm{x}$-axis is based on a $\log _{10}$ scale for copy number derived from 10 -fold serial dilutions of each plasmid standard; $y$-axis represents critical threshold, where fluorescence was measured and used to construct curve
rDNA gene increased with increasing histology scores of $0-3$, but decreased with histology scores of $4-5$. The observed decrease occurred gradually for the Hsp 70 gene and was abrupt for the 18S rDNA gene. The copy number for the Hsp 70 and 18S rDNA sequences ranged from $0-1880$ and $0-11200$, respectively (Fig. 2). Significant correlation ( $\leq \leq 0.01$ ) between mean histology scores and mean genetic copy number did not occur when analyzed from 0-5 for either the Hsp $70\left(\mathrm{R}^{2}=0.74, \mathrm{p}<0.03\right)$ or the $18 \mathrm{~S}$ rDNA $\left(\mathrm{R}^{2}=0.54\right.$, $\mathrm{p}<0.09$ ) sequences. However, the mean copy number did correlate significantly $\left(\mathrm{R}^{2}=0.96, \mathrm{p}=0.003\right)$ with mean histology scores of $0-4$ for the Hsp 70 sequence. This correlation was not found between histology scores (0-4) and copy number for the 18S rDNA gene.

Table 3. Oncorhynchus mykiss. Histology, PCR and QPCR analysis of rainbow trout exposed to Myxobolus cerebralis under natural river conditions. Results from single and nested PCR analysis were combined and used to calculate PCR positive column. * Significant differences compared to histology

\begin{tabular}{|lcccc|}
\hline \multirow{2}{*}{$\begin{array}{l}\text { Histology } \\
\text { score }\end{array}$} & \multirow{2}{*}{$\begin{array}{c}\text { Positive by } \\
\text { histology }\end{array}$} & $\begin{array}{c}\text { PCR } \\
\text { positive }\end{array}$ & Hsp 70 & QPCR \\
\cline { 4 - 5 } & & & 18DNA \\
\hline 0 & $0 / 32$ & $9 / 32^{*}$ & $9 / 32^{*}$ & $9 / 32^{*}$ \\
1 & $9 / 9$ & $9 / 9$ & $9 / 9$ & $9 / 9$ \\
2 & $10 / 10$ & $10 / 10$ & $10 / 10$ & $10 / 10$ \\
3 & $11 / 11$ & $11 / 11$ & $11 / 11$ & $11 / 11$ \\
4 & $33 / 33$ & $33 / 33$ & $33 / 33$ & $33 / 33$ \\
5 & $12 / 12$ & $12 / 12$ & $12 / 12$ & $12 / 12$ \\
\hline
\end{tabular}

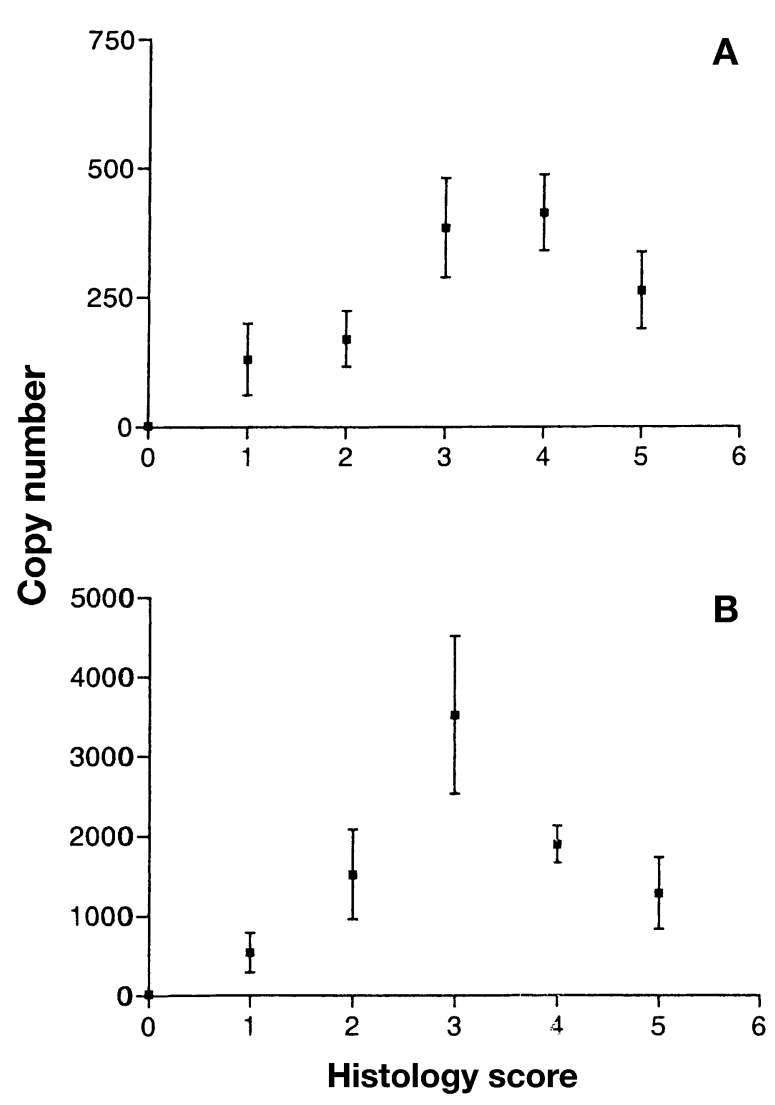

Fig. 2. Distribution of histology score versus copy number for (A) Hsp 70 and (B) 18S rDNA assays for Myxobolus cerebralis. Variation presented as standard error about the mean 


\section{DISCUSSION}

Methods currently used to identify Myxobolus cerebralis and measure infection severity within infected fish can be time-consuming, labor-intensive and often subjective in their ability to distinguish the parasite from other myxozoan species. To improve diagnostic capabilities for this parasite, real-time QPCR assays targeting the Hsp 70 and 18S rDNA genes of $M$. cerebralis were developed. Sensitivity, specificity and potential correlation of assay results to infection severity (as measured by histology scores) were investigated using rainbow trout fry exposed to the parasite under natural river conditions.

In the present study, specificity of a QPCR analysis for Myxobolus cerebralis using 18S rDNA and Hsp 70 probe/primers was verified by testing cross-reactivity with DNA extracted from 20 uninfected rainbow trout (negative controls) and 5 fish parasites. No amplified product was observed for host or non-M. cerebralis DNA, suggesting that both primer/probe combinations were specific for the target sequences. Assay sensitivity was determined by examining single TAM spores and through serial dilution of DNA extracted from 20 TAM spores. Sensitivity was further defined by comparing with histology and standard PCR. Both QPCR assays were capable of detecting single spores and nucleic acids with a sensitivity of 12.5 and $6.3 \mathrm{pg} \mathrm{pl}^{-1}$ for the Hsp 70 and 18S rDNA genes, respectively; $28 \%$ of rainbow trout $(n=9 / 32)$ determined negative by histology were recognized as positive for infection by QPCR and traditional PCR analysis. These observations further demonstrate the increased sensitivity of PCR-based methodology over histological techniques when identifying this parasite. The results also demonstrate that QPCR analysis can detect small quantities of DNA and appears to be as sensitive as other PCRbased tests.

When characterizing potential carrier state and level of infection in fish populations, histology scores for Myxobolus cerebralis are often assigned. Analysis by QPCR showed that the parasite copy number was correlated to histology scores. This relationship was varied, and a significant linear correlation was found only for the Hsp 70 probe/primer set at histology scores from $0-4$, but no correlation was observed when comparing scores from $0-5$ for either probe/primer set (Fig. 2). At higher histology scores, a drop in copy number was observed for the Hsp 70 and 18S rDNA sequences. The reason for such a decrease is unclear, but could be related to extraction inefficiencies at high parasite levels, the stimulation of a host immune response to infection, and/or inadvertent sampling bias (histology only provides a cross-sectional observation). Pathological conditions associated with increas- ing infection intensity by $M$. cerebralis include formation of myxospores and leukocyte infiltration around infected tissues (Andree et al. 2002). As myxospores begin to form, the ability to effectively extract nucleic acids decreases (Andree et al. 1997). Therefore, increasing parasite burden associated with elevated infection severity may have resulted in decreased extraction efficiency. The efficiency of extraction was consistent between different tubes. Although fish were sampled at 900 CTUs following exposure, spore development at high infection levels would be greater, and consequently the quantity or efficiency of DNA extraction may have been compromised due to the presence of mature spores. Alternatively, since increased histology scores can represent leukocyte infiltration associated with high infection levels (Andree et al. 2002), such a host response may reduce pre-spore developmental stages and spore numbers but fish may still exhibit high histology scores. A final possibility that might explain the decrease in copy number at high histology scores could relate to parasite distribution within the cranial region. This distribution probably varies and could create a sampling bias between that half of the head examined for histology and that half processed for PCR and QPCR analyses. Although a PTD analysis might have clarified some of these interpretations, this method could not be incorporated due to limited spore development during the period used to generate infected material and the sampling regime employed in this study.

As stated, a significant linear correlation between copy number and histology scores of $0-4$ was identified for the Hsp 70 sequence. This observation indicates a potential for combining QPCR diagnostics with a measure of infection severity, but further testing is required to validate this. Until recently, the scale of infection used by many researchers and diagnostic laboratories was based on a scale of 0-4 (Hedrick et al. 1999, Baldwin et al. 2000) rather than 0-5. The previous scale may correlate better with QPCR results, but variability may still occur. Testing of fish infected with the parasite at various life stages is needed.

Overall, the parasite copy number obtained from the Hsp 70 sequence was consistently lower (0-1880) than that detected using the 18S rDNA sequence $(0-11200)$. It has been suggested that 104 copies of the $18 \mathrm{~S}$ rDNA sequence are present in the genome of mature Myxobolus cerebralis spores (Kelley et al. 2004), but the copy number of the Hsp 70 gene is currently unknown. Our data suggest that the Hsp 70 gene may be found in lower numbers than the $18 \mathrm{~S}$ rDNA gene. Previous studies have demonstrated that single TAM spores can contain 6 structural cells and up to 64 sporoplasms capable of infecting a susceptible host (El-Matbouli et al. 1995); therefore a minimum of 
70 copies per spore could have been demonstrated from an individual TAM spore. Although both primer/ probe sets developed for QPCR analysis were capable of detecting single TAM spores, copy number ranged between 1 and 7 per spore. The above discrepancy is probably a result of an inability to extract and capture total DNA from spores using the denaturing protocol employed.

This study has demonstrated that during early stages of infection (900 CTUs), QPCR is a sensitive detection method, and could potentially predict infection severity at histology scores of 4 and below using an Hsp 70 probe/primer set. Although the 18S rDNA PCR was more sensitive $\left(6.3 \mathrm{pg} \mathrm{pl}^{-1}\right)$ when detecting the parasite than the Hsp 70 PCR (12.5 $\mathrm{pg} \mathrm{pl}^{-1}$ ) under the reaction conditions tested, significant correlation between copy number and histology scores up to 4 were only found for the Hsp 70 sequence. These data suggest that QPCR would be a useful tool for detecting Myxobolus cerebralis in infected samples and might provide a relative indication of infection severity. Advantages from a technique of this type include a high degree of sensitivity associated with PCR methodology, high sample throughput, and the ability to detect and quantify target sequences within a 1-step process. However, it should be noted that in situations where regulatory actions may result from diagnosis of $M$. cerebralisinfected fish, all molecular assays should be coupled with traditional diagnostic techniques to avoid misdiagnosis.

The results of this study demonstrate the potential for QPCR to be used as a detection method for Myxobolus cerebralis. Future testing should include additional fish pathogens that may co-occur with $M$. cerebralis and controlled laboratory experiments with fish exposed to known spore concentrations. Fish should be sampled over the course of an infection to better identify relationships between copy number and infection severity. In addition, examining DNA from mature myxospores, infection within the secondary host (Tubifex tubifex), and testing of water samples would further validate the range of applications for this technique.

Acknowledgements. The authors would like to thank C. Anderson and P. Simpson of the University of Idaho for laboratory and technical support. We would like to thank E. MacConnell and C. Whipps for providing triactinomyxon spores for analysis. We would also like to thank K. A. Johnson, C. Hogge, C. Cegelski and M. Cambell of the Eagle Fish Health Laboratory and B. Dennis of the University of Idaho (Statistics Department) for critical reviews of this manuscript. This project was funded in part through the Whirling Disease Foundation and the National Partnership on the Management of Wild and Native Coldwater Fisheries (USDI/USFWS Award \# 98210-0-G642). The Lower Snake River Compensation Plan and Idaho Power Company provided additional support.

\section{LITERATURE CITED}

Andree KB, Gresoviac SJ, Hedrick RP (1997) Small subunit ribosomal RNA sequences unite alternate actinosporean and myxosporean stages of Myxobolus cerebralis the causative agent of whirling disease in salmonid fish. J Eukaryot Microbiol 44:208-215

Andree KB, MacConnell E, Hedrick RP (1998) A nested polymerase chain reaction for the detection of genomic DNA of Myxobolus cerebralis in rainbow trout Oncorhynchus mykiss. Dis Aquat Org 34:145-154

Andree KB, Hedrick RP, MacConnell E (2002) A review of the approaches to detect Myxobolus cerebralis, the cause of salmonid whirling disease. Am Fish Soc Symp 29:197-211

Altschul SF, Madden TL, Schaffer AA, Zhang J, Zhang Z, Miller W, Lipman DJ (1997) Gapped BLAST and PSIBLAST: a new generation of protein database search programs. Nucleic Acids Res 25:3389-3402

Baldwin TJ, Myklebust KA (2002) Validation of a single round polymerase chain reaction assay for identification of Myxobolus cerebralis myxospores. Dis Aquat Org 49: 185-190

Baldwin TJ, Vincent RE, Silflow RM, Stanek D (2000) Myxobolus cerebralis infection in rainbow trout (Oncorhynchus mykiss) and brown trout (Salmo trutta) exposed under natural stream conditions. J Vet Diagn Investig 12:312-321

Bartholomew JL, Reno PW (2002) The history and dissemination of whirling disease. Am Fish Soc Symp 29:3-24

Bialek R, Ibricevic A, Fothergill A, Begerow D (2000) Small subunit ribosomal DNA sequence shows Paracoccidioides brasiliensis closely related to Blastomyces dermatitidis. J Clin Microbiol 38:3190-3193

Bilodeau LA, Waldbieser GC, Terhune JS, Wise DJ, Wolters WR (2003) A real-time polymerase chain reaction assay of the bacterium Edwardsiella ictaluri in channel catfish. J Aquat Anim Health 15:80-86

Cavender WP, Johnson KA, Cain KD (2003) Distribution of Myxobolus cerebralis within a free-flowing river system during the migration period for juvenile anadromous salmonids in Idaho. J Aquat Anim Health 15:158-166

Corbeil S, McColl KA, Craine MJ (2003) Development of a TaqMan quantitative PCR assay for the identification of Piscirickettsia salmonis. Bull Eur Assoc Fish Pathol 23: 95-101

del Cerro A, Mendoza MC, Guijarro JA (2002) Usefulness of a TaqMan-based polymerase chain reaction assay for the detection of the fish pathogen Flavobacterium psychrophilium. J Appl Microbiol 93:149-156

El-Matbouli M, Hoffmann RW, Mandok C (1995) Light and electron microscopic observations on the route of the triactinomyxon-sporoplasm of Myxobolus cerebralis for epidermis into rainbow trout cartilage. J Fish Biol 46:919-935

Epp JK, Wood JS, Milton JB (2002) New PCR test for Myxobolus cerebralis based on a heat-shock protein gene. In: Proceedings 8th Annual Whirling Disease Symposium, Denver, CO, p 61-62

Feder ME, Hofmann GE (1999) Heat-shock proteins, molecular chaperones, and the stress response: evolutionary and ecological physiology. Annu Rev Physiol 61:243-282

Hedrick RP, McDowell TS, Gay M, Marty GD, Georgiadis MP, MacConnell E (1999) Comparative susceptibility of rainbow trout Oncorhynchus mykiss and brown trout Salmo trutta to Myxobolus cerebralis, the cause of salmonid whirling disease. Dis Aquat Org 37:173-183

Hillis DM, Dixon MT (1991) Ribosomal DNA: molecular evolution and phylogenetic inference. Q Rev Biol 66:411-446 
Hoffman GL (1990) Myxobolus cerebralis, a worldwide cause of salmonid whirling disease. J Aquat Anim Health 2:30-37

Hoffman GL (1999) Parasites of North American freshwater fishes, 2nd edn, Cornell University Press, Ithaca, NY

Kelley GO, Francisco J, Vergara Z, Leutenegger CM and 7 others (2004) Evaluation of five diagnostic methods for the detection and quantification of Myxobolus cerebralis. J Vet Diagn Investig 16:195-204

Lorz HV, Amandi A (1994) Parasitic diseases of fish. VI. Whirling disease of salmonids. In: Thoesen JC (ed) Suggested procedures for the detection and identification of certain finfish and shellfish pathogens, 4th edn, American Fisheries Society, Fish Health Section, Bethesda, MD

Markiw EM, Wolf K(1974) Myxosoma cerebralis: isolation and concentration from fish skeletal elements - sequential enzymatic digestions and purification by differential centrifugation. J Fish Res Board Can 31:245-251

Nehring RB, Walker PG (1996) Whirling disease in the wild: the new reality in the intermountain west. Fisheries 21: $28-30$

Editorial responsibility: Carey Cunningham, Aberdeen, UK
Noga EJ (1996) Fish diseases: diagnosis and treatments, Mosby-Year Book, Missouri

Overturf K, LaPatra S, Powell M (2001) Real-time PCR for the detection and quantitative analysis of IHNV in salmonids. J Fish Dis 24:325-333

Schisler GJ, Bergersen EP, Walker PG, Wood J, Epp JK (2001) Comparison of single-round polymerase chain reaction (PCR) and pepsin-trypsin digest (PTD) methods for detection of Myxobolus cerebralis. Dis Aquat Org 45:109-114

Vincent ER (1996) Whirling disease and wild trout: the Montana experience. Fisheries 2:32-33

Walker PG, Nehring RB (1995) An investigation to determine the cause(s) of the disappearance of young wild rainbow trout in the upper Colorado River, in Middle Park, Colorado. Colorado, Division of Wildlife, Denver, CO

Yin LJ, Shackel NA, Zekry A, McGuinness PH and 5 others (2001) Real-time reverse transcriptase-polymerase chain reaction (RT-PCR) for measurement of cytokine and growth factor mRNA expression with fluorogeneic probes or SYBR Green I. Immunol Cell Biol 79:213-221

Submitted: November 11, 2003; Accepted: April 13, 2004 Proofs received from author(s): August 20, 2004 